\title{
PERANCANGAN SISTEM PRESENSI MERESPON POLA SIDIK JARI DARI SENSOR FINGERPRINT
}

\author{
B. S. Rahayu Purwanti ${ }^{1}$, Fathan Ayyasy Mursyid ${ }^{2}$ dan Senja Deva Rizki \\ Kusmujianti $^{3}$ \\ 1,2,3) Jurusan Teknik Elektro, Politeknik Negeri Jakarta \\ Email:11)rahayu.purwanti@elektro.pnj.ac.id
}

\begin{abstract}
ABSTRAK
Penelitian ini membahas perancangan system presensi yang didesain terkoneksi ke solenoid pengunci model pintu ruangan. Permasalahan dalam artikel ini dilatarbelakangi tindakan mahasiswa, kecurangan mengubah tanda tidak hadir "0" menjadi hadir "1" pada Formulir Kehadiran. Tindakan mahasiswa penting diminimalisir untuk antisipasi semakin meluasnya kecurangan. Sistem presensi finger print telah dikenal penggunaannya di kantor, sekolah, hotel, dan pabrik. Bahkan telah dipasang di beberapa layanan umum misalnya rumah sakit, bank, taman nasional serta di beberapa sarana prasarana umum lainnya. Identifikasi pola sidik jari dapat merekam data kehadiran mahasiswa, dosen di ruang kelas. Metode absen manual dengan menandai 1 (hadir) dan 0 (tidakhadir), sudah saatnya berbasis teknologi. Hal ini penting untuk membantu petugas admin dapat menginput datapresensi ke Unisys sesuai Form Daftar Hadir Mahasiswa. Perancangan system presensi melalui identifikasi pola sidik jari mengadopsi cara kerja Unisys. Jari yang teridentifikasi oleh sensor solenoid mentriger terbukanya pintu ruang kelas. Pola sidik jari sebelumnya telah didaftarkan terlebih dahulu dan terdata di database. Akses database secara wireless oleh modul ESP8266. Data yang tersimpan di database adalah nama, ID fingerprint, NIM, dan waktu masuk. Setelah data berhasil terinput ke database, solenoid door lock dan motor servo aktif untuk membuka pintu. Pintu tertutup secara otomatis ketika limit switch aktif. Selenoid mendapat trigger dan pintu terbukan otomatis. Perancangan system presensi telah berhasil merespon 6 posisi pola sidik jari (fingerprint), teridentifikasi sesuai databse. Respon posisi sidik jari juga telah terintegrasi pada buka/ tutup model pintu dengan pengunci selenoid.
\end{abstract}

Katakunsi: database, ESP8266. fingerprint, presensi, solenoid.

\section{PENDAHULUAN}

Kehadiran mahasiswa dan dosen pada pelaksanaan Proses Belajar mengajar (PBM) di Politeknik Negeri Jakarta (PNJ) masih manual. Caranya dengan menandai 1 (hadir) dan 0 (tidak hadir). Presensi manual rawan dicurangi, tanda 0 diubah menjadi 1 oleh mahasiswa yang tidak bertanggung jawab. Kecurangan mahasiswa tersebut sulit dilacak, tanpa bukti, dan mustahil diberi sanksi. Pembuktian si pengubah data presensi hanya diperoleh dari dugaan atau logika persepsi yang hampir dapat dipastikan kebenaran pelakunya. Azas praduga tak bersalah seolah menjadi boomerang bagi petugas admin, sementara si pengubah tenang tanpa rasa bersalah. Petugas admin menginput data ke Unisys sesuai data presensi di Form Daftar Hadir Mahasiswa. Walaupun kemungkinan telah diubah oleh oknum mahasiswa. Setelah seluruh data terinput, Unisys menampilkan berbagai informasi di layar komputer secara langsung. Informasi tersebut berkaitan dengan aktivitas pembelajaran yang telah dilakukan mahasiswa bersama dosen. Permasalahan ini telah menginspirasi untuk meminimalisasi celah temuan kecurangan mahasiswa. Oleh karena itu, perlu dibuat sistem identifikasi yang realtime (on time in time) mendata kehadiran mahasiswa. Tujuan penelitian adalah merekam data kehadiran yang tidak memungkinkan direkayasa akibat kecurangan. Metode penelitiannya dengan merancangbangun system yang memanfaatkan sensor fingerprint. 
Instrumen pendetekasi mengenali pola sidik jari dengan metode optikal, sensor fingerprint mendeteksi kontur tinggi rendahnya permukaan pola sidik jari dan listrik statis tubuh [1]. Pendapat yang sama [2], tentang sensor optic fingerprint mendeteksi sidik jari pengguna dengan merekam/men-scan ujung jari yang diterangi cahaya. Pantulan cahaya dari ujung jari ditangkap oleh fingerprint scanner dan menyimpannya di memori. Sensor optik ini memperoleh instruksi dari mikrokontroler, sebagai pengolah data hasil deteksi sensor. Hasil deteksinya disimpan ke dalam database pada cloud server. Salah satu aplikasinya adalah cloud storage yang merupakan layanan penyimpanan data secara online di storage server [3]. Saat verifikasi, pola sidik jari dicocokkan dengan hasil scan yang tersimpan di memori [4]. Hasil identifikasi sesuai pola fitur sidik jari unik (minutiae) yang telah terdaftar/ tersimpan sebelumnya. Pola minutiae disimpan dalam memory atau database. Saat verifikasi, pola minutiae dicocokkan dengan hasil scan sidik jari yang telah dilakukan saat awal pendataan. Hasil scan pola sidik jari dari pendataan ini menjadi data pendaftar. dan sumber verifikasi jika sensor mengirimkan data ke mikrokontroler. Data sensor ditransmisikan oleh modul ESP8266 menuju komputer client [5]. Rele yang terhubung ke solenoid door lock on [6], sehingga pintu terbuka. Penggerak pintu dengan motor servo berputar dua arah sesuai dengan sudut gerakan rotornya. Pengaturan gerakan motor servo [7] dengan menubah duty cycle sinyal Pulse Width Modulation (PWM) pada bagian pin kontrolnya [8]. Closed feedback pada rangkaian control motor servo, terdiri dari sebuah motor, serangkaian gear, potensiometer, dan rangkaian kontrol pengendali gerakan putar rotor pada motor servo [9] dengan nilai PWM. Sinyal luaran output motor servo dapat men-trigger komponen lainnya pada suatu sistem. Sementara itu, data yang terinput kedalam database merupakan output dari sensor yaitu solenoid. On-nya selenoid men-trigger motor servo. Gerakan servo sesuai set sudut untuk membuka/ menutup model pintu secara otomatis. Instruksi buka/tutup melalui program pada mikrokontroler NodeMCU, produk Internet of Things (IoT), berbasis Firmware Lua dan system on a chip (SoC) ESP8266-12E [10].

Perancangan alat/sistem terdiri dari hardware (sensor fingerprint, solenoid door look, motor servo, Arduino Uno dan ESP8266) dan software Arduino IDE. Rangka alat terbuat dari kayu. Sensor fingerprint berada di standing pintu dan komponen kontrol berada didalam box. Sensor fingerprint mendeteksi pola sidik jari. Pola sidik jari mahasiswa di daftar/enroll terlebih dahulu dan disimpan di memori. Saat verifikasi pola sidik jari berhasil, sensor mengirim data ke Arduino Uno. Data sensor diolah Arduino Uno dan mentransmisi output mikrokontroler ke dalam database melalui server ESP8266. Personal Computer yang difungsikan sebagai server menampilkan informasi ID, nama, kehadiran dan kompensasi. Output Arduino Uno berupa logik sebagai input relay. Relay sebagai on/off solenoid. Setelah solenoid aktif motor servo otomatis membuka pintu. Motor servo diatur pergerakannya dengan program pada software Arduino IDE. Capture pola sidik jari dilihat menggunakan aplikasi SFG v2.0. Aplikasi SFG dapat dioperasikan setelah terkoneksi ke Arduino Uno dan sensor fingerprint. 


\section{METODE PENELITIAN}

Langkah-langkah solusi permasalahan, untuk perancangan system presensi finger print mengacu pada:

Flowchart (Gambar1) uang memuat diagram alir system identifikasi, buka/ tutup pengunci solenoid pada model pintu, dan desain perancangan penampil dengan web cloud.

Blok Diagram (Gambar 2); terdiri dari komponen-komponen dan modul-modul pendukung system. Yaitu: input dari sensor, pemroses data input dengan mikrokontroler, dan penampil data sebagai output system.

Menurut Joyner R. Oroh, dkk. (2014), empat pola dasar Dermatoglyphic tentang sidik jari adalah; Whorl atau Swirl, Arch, Loop, dan Triradius. Pola lainnya, merupakan variasi dan kombinasi keempatnya. Setiap orang mungkin memiliki Whorl, Arch, atau Loop di setiap ujung jari yang berbeda, atau mungkin Triradius pada gunung dari Luna dan di bawah setiap jari. Mayoritas orang mempunyai pola dua Whorl atau Loop di jari tangan lainnya. Cara kerja identifikasi dengan metode optical scanning pola jari (Gambar 3), sehingga setiap sidik jari sesorang berbeda.

\section{HASIL DAN PEMBAHASAN}

\section{Pola Sidik Jari yang Sudah Terdaftar}

Menurut Purwanti [11], ID pola sidik jari sesuai waktu identifikasi(Gambar 4), terverifikasi atau tidaknya pola sidik jari (Gambar 5), ditampilkan pada software SFG Demo V2.0 (Gambar 6).

Hasil identifikasi pola sidik jari sesuai posisi (Tabel 1) untuk telunjuk dan ibu jari. Pengambilan data waktu (detik) identifikasi secara otomatis, dengan aplikasi software SFG Demo V2.0. Ibu jari yang terlalu kering atau terlalu basah, serta posisi scan yang tidak tepat berpengaruh terhadap hasil identifikasi. Pola fitur sidik jari unik (minutiae), minutiae yang jelas alurnya lebih cepat menemukan data ID pada database melalui sensor fingerprint. Demikian sebaliknya, sidik jari tidak jelas alurnya akibat kering/basah lebih lama teridentifikasi. Berbagai posisi pola sidik jari direkam waktu deteksinya, waktu deteksi tercepat percoban ke 3. Hal tersebut dikarenakan posisi dan gambar pola sidik jari jelas alurnya.

Media uji system presensi dengan mendeteksi identitas sidik jari, sampel beberapa jari anggota peneliti (Tabel 1). Tujuannya untuk verifikasi keandalan program yang dirancang terkoneksi ke web server.

Keterangan Tabel 1:

Benar, pola sidik jari terverifikasi dengan pola sidik jari pada database modul fingerprint, salah jika tidak terverifikasi

Gambar 7, koneksi ESP dengan website system absensipnj.web.id berhasil terkoneksi. Hal ini disebabkan ESP terflash dengan benar, dengan perintah AT command yang tepat, dan server web sistemabsensipnj.web.id. yang aktif.

\section{Hasil Pengujian Kompensasi}

Gambar 8, data mahasiswa bernama senja dengan ide jari 334455, terakhir masuk ke dalam sistem pukul 17.30. Waktu masuk data seharusnya pukul 08.00. sehingga terjadi keterlambatan masuk 14 jam dan dikonversi menjadi kompen.

\section{Hasil Pengujian Surat Peringatan}

Gambar 9, data mahasiswa bernama Edo Retho R. dengan ID Jari 2, terakhir masuk ke dalam sistem pukul 15.37. 
Waktu masuk data seharusnya pukul 08.00. sehingga terjadi keterlambatan masuk 15 jam 37 menit dan dikonversi menjadi kompen. Hasil kompen pada sistem, jika lebih dari 10 jam, maka akan dikenakan SP1.

Gambar 10, terlihat tampilan kompen dan SP. Mahasiswa bernama fathan ayyasy mursyid dengan ID jari 1 tidak memiliki SP karena total kompen mahasiswa tersebut 7 jam 43 menit atau masih dibawah 10 jam.

\section{KESIMPULAN}

Penggunaan sistem presensi dengan fingerprint dapat diakses oleh seluruh pola sidik jari yang telah terdaftar ke database. Rata-rata waktu deteksi dan identifikasi sidik jari adalah $43.6 \mathrm{~s}<0,5$ menit, sebagi waktu sampling untuk mengidentifikasi pola sidik jari pada system presensi. Perancangan web server telah berfungsi sebagai penampil data sesuai hasil deteksi dan identifikasi sensor finger print.

\section{UCAPAN TERIMAKASIH}

Ucapan terima kasih disampaikan untuk P3M PNJ yang telah mendanai sehingga penelitian ini terealisasi sesuai target dan tujuan.

\section{DAFTAR PUSTAKA}

[1] Joyner R. Oroh, Elia Kendekallo, Sherwin R. U. A. Sompie, Janny O. Wuwung. 2014. "Rancang Bangun Pengenalan Sidik Jari". Jurnal Teknik Elektro dan Komputer, vol 3 no. 1, hh. 1-7. ISSN 2301-8402.

[2] Akbar Iskandar, Muhajirin, Dan Lisah, 2017, "Sistem Keamanan Pintu Berbasis Arduino Mega”, Jurnal Informatika Upgris, Vol. 3, No. 2, Hal. 99 - 104.
[3] Putri Wulansari. 2015. "Perpustakaan Berbasis Cloud Computing”. Jurnal Iqra, vol. 9, no. 1 , hh. 108-125.

[4] Heni Jusuf, Ariana Azimah, Dan Winarsih, 2013, "Pengembangan Aplikasi Sistem Absensi Dosen Dengan Menggunakan Fingerprint (Sidik Jari Digital) Di Universitas Nasional”, Rekayasa Teknologi, Vol. 5, No. 1, Hal. 7 12.

[5] Isa Albana Dan Anton Harjito, 2016, “Analisa Pola Pengiriman Paket Data Multi Sensor Dan Kebutuhan Energi Pada Rancang Bangun Sistem Internet Of Things Berbasis ESP-8266", Seminar Nasional Sains Dan Teknologi Terapan Institut Teknologi Adhi Tama Surabaya, Hal. C-69 -C-74, ISBN 978-602-98569-1-0.

[6] Helmi, Guntor, Yoyo Somantri, Erik Haritman. 2013. "Rancang Bangun Magnetic Door Lock Menggunakan Keypad Dan Solenoid Berbasis Mikrokontroller Arduino Uno". ELECTRANS. 2013; 12 (1): 39-48.

[7] Anwar Mujadin Dan Dwi Astharini, 2016, “Uji Kinerja Modul Pelatihan Motor Penunjang Mata Kuliah Mekatronika”. Jurnal Al-Azhar Indonesia Seri Sains Dan Teknologi, Vol. 3, No.3, Hal. 127 - 133.

[8] Sujarwata, 2013, "Pengendali Motor Servo Berbasis Mikrokontroler Basic Stamp 2SX untuk Mengembangkan Sistem Robotika”, Angkasa, Vol. V, No. 1, Hal. 47 - 54.

[9] Terhulin Purba Tambak Dan T. Ahri Bahriun. 2015. "Perancangan Sistem Home Automation Arduino Uno". Singuda Ensikom. Vol. 10. No. 28. Hal. 121 -126. 
[10] Agus Wagyana, Zulhelman. 2016. "Prototype Smart Power Outlet untuk Pencegah Kebakaran Akibat Arus Listrik". Prosiding SENTIA Politeknik Negeri Malang, vol. 8, hh. 86-92. ISSN: 2085-2347

[11] Senja Deva Rizki Kusmujianti, Fathan Ayyasy Mursyid, B. S.
Rahayu Purwanti 2018. Identifikasi Pola Sidik Jari dengan Modul Fingerprint pada Desain Sistem Presensi. Publikasi Oral pada Seminara Nasional Teknik Elektro, Desember Tahun 2018. 


\section{LAMPIRAN}

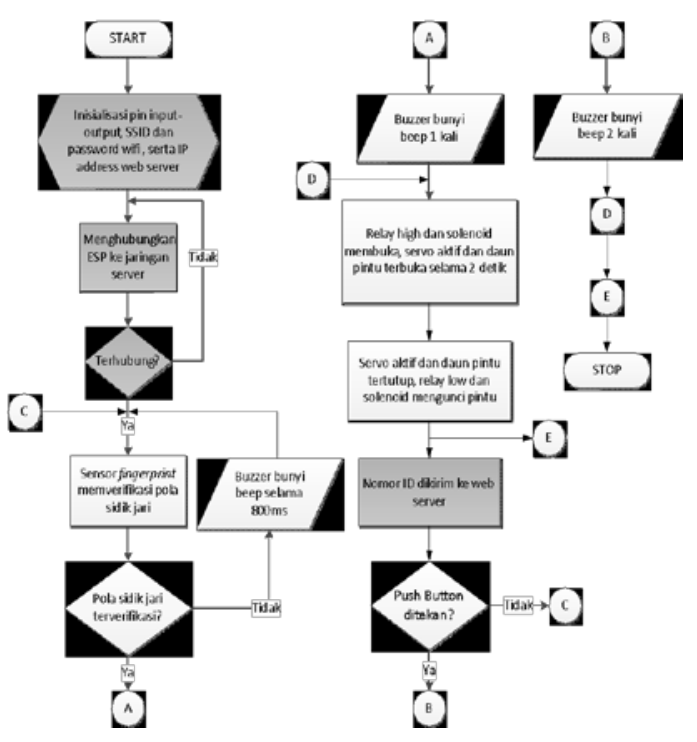

Gambar 1 Flowchart

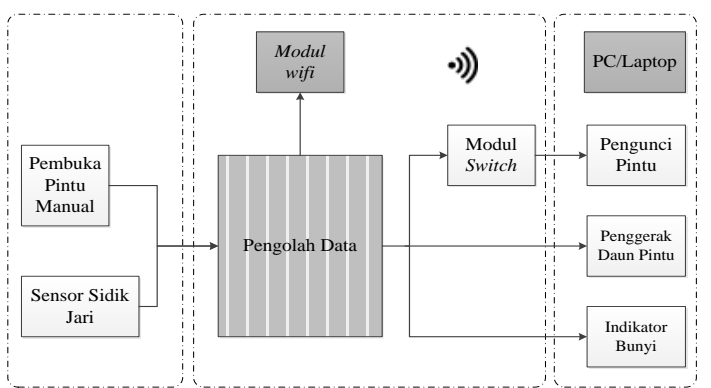

Gambar 2 Diagram Blok

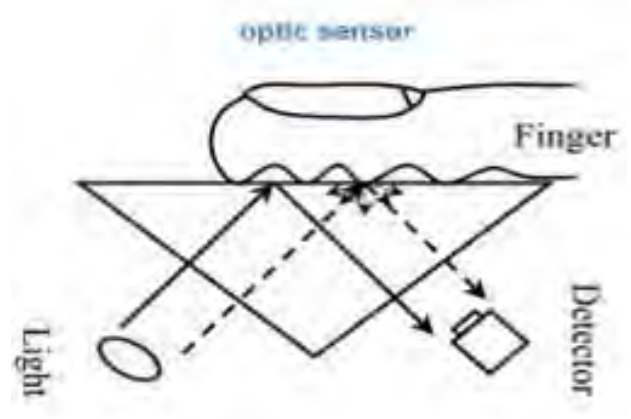

Gambar 3 Metode Optikal Scanning [1]

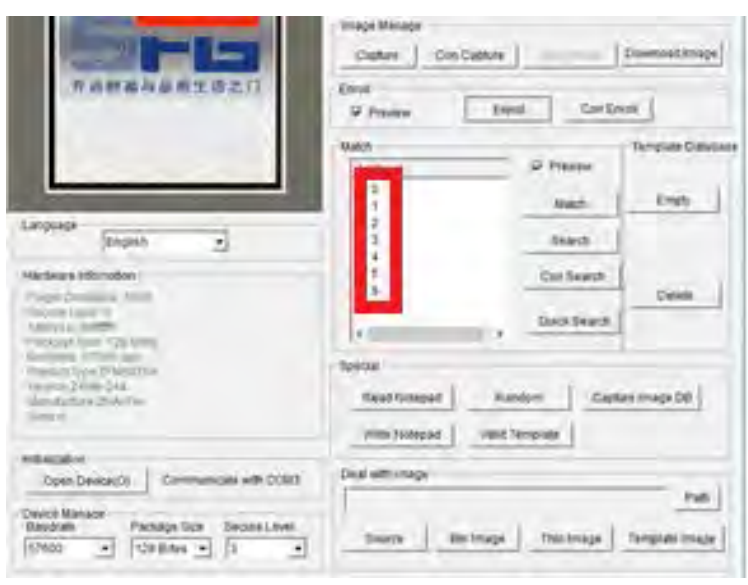

Gambar 4 ID Pola Sidik Jari

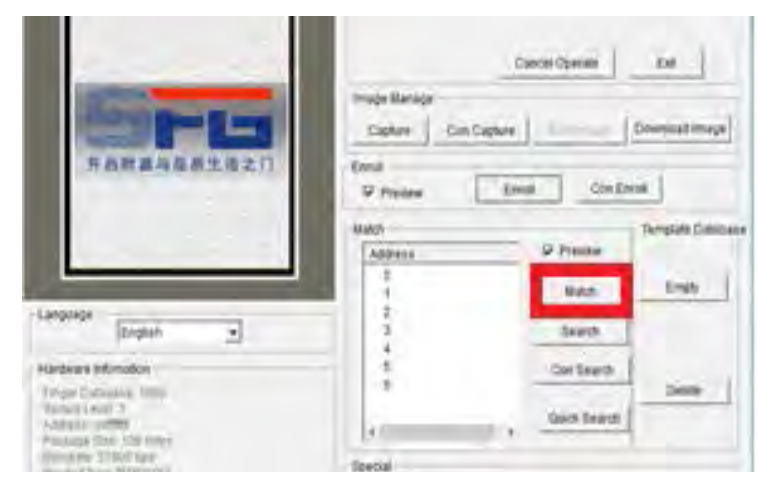

Gambar 5 Menu Aplikasi Match SFG Demo V2.0

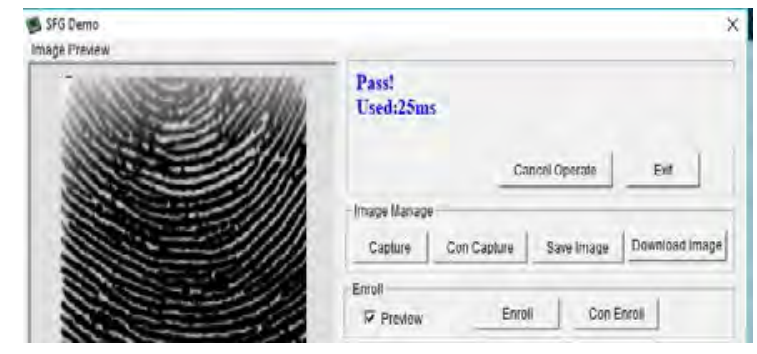

Gambar 6 Verifikasi Pola Sidik Jari

Tabel 1 Pengujian Waktu Deteksi Pola Sidik Jari

\begin{tabular}{cccc}
\hline $\begin{array}{c}\text { Posisi Ibu } \\
\text { jari Kanan }\end{array}$ & $\begin{array}{c}\text { Pola } \\
\text { Sidik Jari }\end{array}$ & $\begin{array}{c}\text { Waktu } \\
\text { Deteksi }\end{array}$ & Ket. \\
\hline & 25 & 25 & benar \\
& & 24 & $\begin{array}{c}\text { *benar, } \\
\text { paling } \\
\text { cepat }\end{array}$ \\
\hline
\end{tabular}



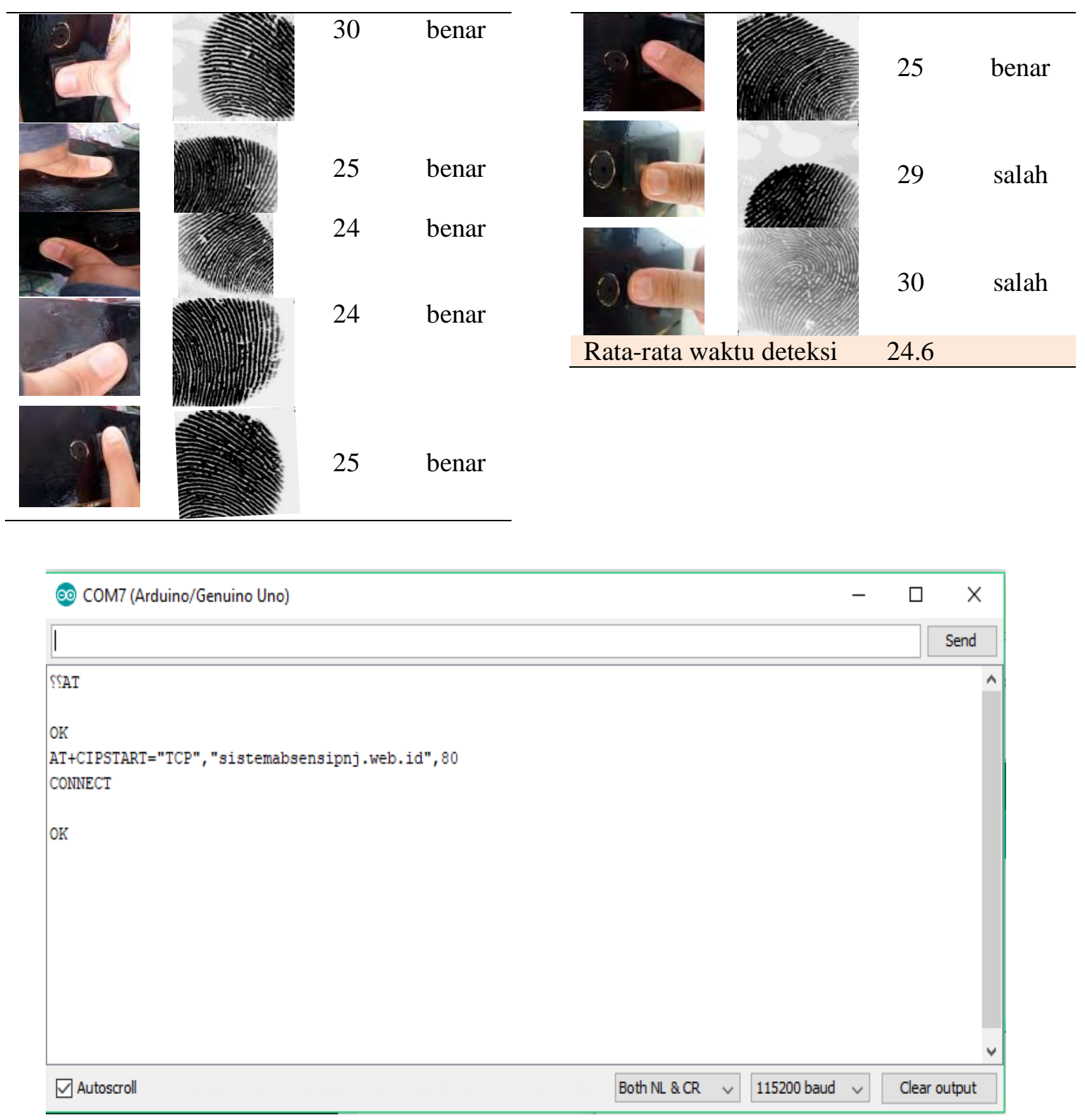

Gambar 7 Serial Monitor Arduino

PAESENSI MAHASISWA

Shev is tenties

Sesth:

\begin{tabular}{|c|c|c|c|c|c|c|c|c|c|c|}
\hline POCANA & $\ln 1$ & 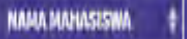 & krus & f & vaktuMaseX & f & VAKTUADSELSI & kowery & $5 p$ & MSI \\
\hline 324455 & D1501002? & scrija & EC 6 A & & 08:00:00 & & $2018072817: 01203$ & 14 Jam 56 Marit & & 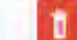 \\
\hline 204455 & 1.115U1003t & миija & $E C_{6 A}$ & & 03:00:100 & & 2018-0l-2517:0054 & $14 \operatorname{Jam} 2$ Menil & & \\
\hline
\end{tabular}




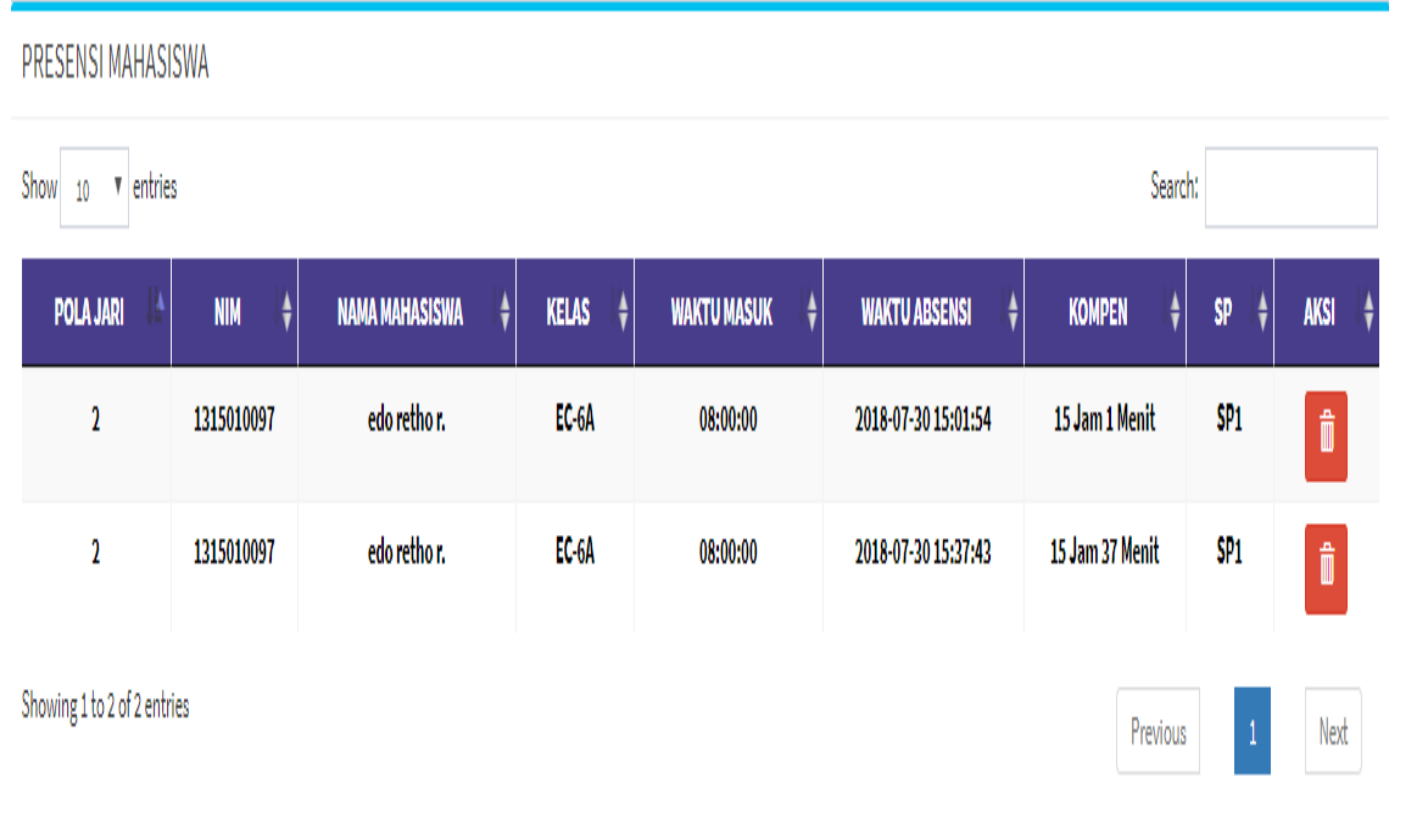

Gambar 9 Hasil Perhitungan SP1

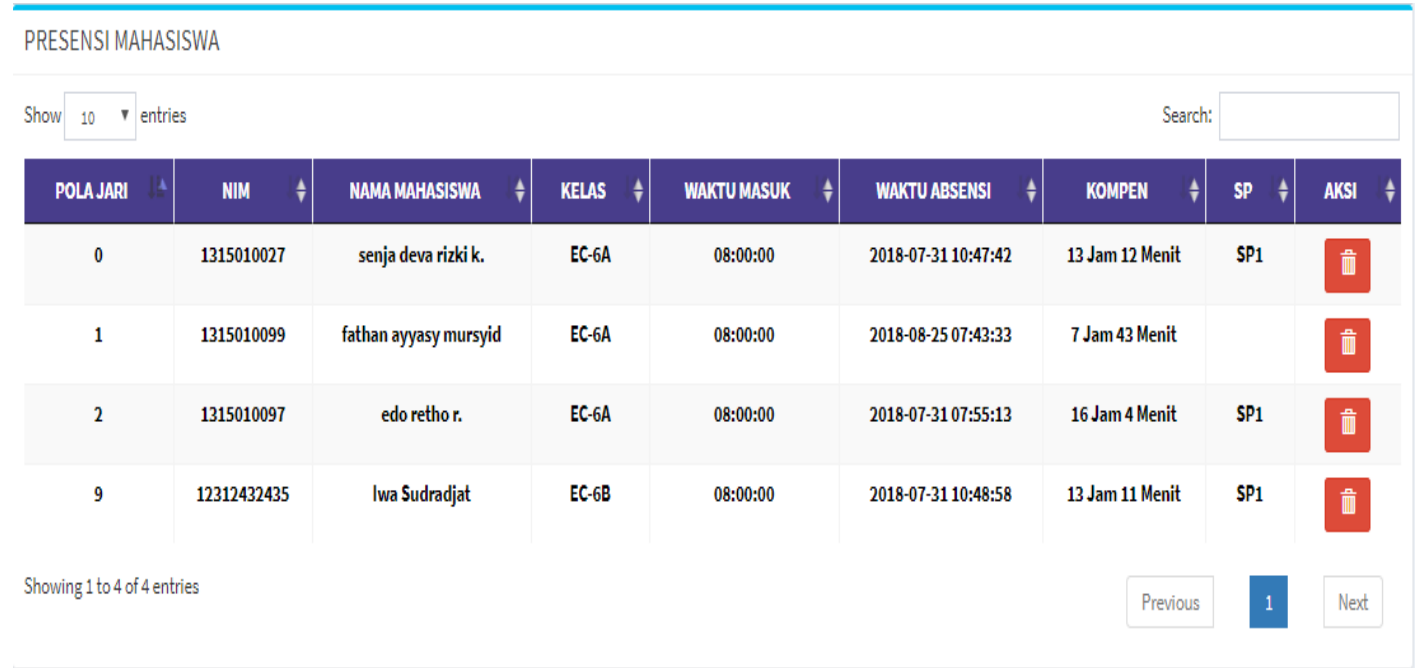

Gambar 10 Hasil Perhitungan SP2 